\title{
Albino Mice as an Animal Model for Infantile Nystagmus Syndrome
}

\author{
Ghislaine L. Traber, ${ }^{1,5}$ Chien-Cheng Chen, ${ }^{2,5}$ Ying-Yu Huang, ${ }^{2,3,5}$ Marcella Spoor, ${ }^{4}$ Jeanine Roos, ${ }^{4}$ \\ Maarten A. Frens, ${ }^{4}$ Dominik Straumann, ${ }^{2,5,6}$ and Christian Grimm ${ }^{1,5,6}$
}

Purpose. Individuals with oculocutaneous albinism are predisposed to visual system abnormalities affecting the retina and retinofugal projections, which may lead to reduced visual acuity and Infantile Nystagmus Syndrome (INS). Due to absence of an established mammalian animal model, mechanisms underlying INS remain elusive. In this study, we screened wild-type mice of varying pigmentation for ocular motor abnormalities in order to identify a possible mouse model for INS.

Methods. Three albino mouse strains (CD1, BALB/c, DBA/1), and two normally pigmented strains (129S6, C57BL/6) were screened using infrared oculography. Varying visual stimuli (black or white background, stationary pattern, optokinetic, i.e., horizontally rotating pattern) were displayed to the full (fVF) or anterior visual field (aVF) of the restrained mouse.

Results. We found spontaneous nystagmus, specifically jerks and oscillations, in albino mice under all experimental conditions. Median eye velocity was between 0.8 and 3.4 $\mathrm{deg} / \mathrm{s}$, depending on the strain. In contrast, the eyes in pigmented mice were nearly stable with a median absolute eye velocity of below $0.4 \mathrm{deg} / \mathrm{s}$. In albino mice, fVF optokinetic stimuli elicited an optokinetic response (OKR) in the correct direction, albeit with superimposed oscillations. However, aVF optokinetic stimuli evoked reversed OKR in these strains, a well known feature of INS.

Conclusions. Based on our results, we endorse the investigated albino mouse strains as new animal models for INS. (Invest Ophthalmol Vis Sci. 2012;53:5737-5747) DOI:10.1167/ iovs.12-10137

From the ${ }^{1} \mathrm{Lab}$ for Retinal Cell Biology, Department of Ophthalmology, and the ${ }^{2}$ Department of Neurology, Zurich University Hospital, Zurich, Switzerland; the ${ }^{3}$ Institute of Molecular Life Sciences, University of Zurich, Zurich, Switzerland; the ${ }^{4}$ Department of Neuroscience, Erasmus Medical Center Rotterdam, Rotterdam, Netherlands; the ${ }^{5}$ Zurich Center for Integrative Human Physiology (ZIHP), Zurich, Switzerland; and the ${ }^{6}$ Center for Neuroscience Zurich (ZNZ), Zurich, Switzerland.

Supported by grants from Gottfried und Julia Bangerter-RhynerStiftung; Stiftung OPOS zugunsten von Wahrnehmungsbehinderten; Hans Imholz-Stiftung; Schweizerischer Fonds zur Verhütung und Bekämpfung der Blindheit; Center for Integrative Human Physiology, University of Zurich; Swiss National Science Foundation; and the Human Frontier Science Program

Submitted for publication May 3, 2012; revised July 9, 2012; accepted July 10, 2012.

Disclosure: G.L. Traber, None; C.-C. Chen, None; Y.-Y. Huang, None; M. Spoor, None; J. Roos, None; M.A. Frens, None; D. Straumann, None; C. Grimm, None

Corresponding author: Ghislaine L. Traber, University Hospital Zurich, Department of Ophthalmology, Frauenklinikstrasse 24, 8091 Zurich, Switzerland; ghislaine.traber@phima.com.

Investigative Ophthalmology \& Visual Science, August 2012, Vol. 53, No. 9 Copyright 2012 The Association for Research in Vision and Ophthalmology, Inc.
Tnfantile Nystagmus Syndrome (INS) is a relatively common Locular motor disorder ${ }^{1,2}$ characterized by involuntary, predominantly horizontal conjugate oscillations of both eyes. The syndrome usually manifests itself within the first six months after birth ${ }^{3,4}$ and remains throughout life. Distinctive features of INS in humans include specific waveforms of eye movement (which is usually a jerk with an increasing slow phase velocity, but which may also be pendular or both), foveation periods, ${ }^{5}$ and inversion of the optokinetic reflex (OKR) ${ }^{6,7}$ Although INS can be idiopathic, a majority of patients have associated visual system abnormalities like albinism, retinal dystrophies, aniridia, optic nerve hypoplasia, or congenital cataracts. ${ }^{1,8,9}$ Due to absence of an appropriate mammalian animal model, the mechanisms underlying INS remain incompletely understood. The known association between albinism and INS prompted us to screen wild-type mice of varying pigmentation for ocular motor abnormalities in order to identify a possible new animal model for INS.

\section{Methods}

All experiments were performed in accordance with the animal welfare guidelines of the Federal Veterinary Office of Switzerland, and experimental procedures were approved by the local authorities (Cantonal Veterinary Office Zurich). Experiments adhered to the ARVO Statement for the Use of Animals in Ophthalmic and Vision Research.

\section{Animals}

CD1 [Crl:CD1(ICR), unpigmented, white; Charles River, Sulzfeld, Germany], BALB/c (BALB/cAnNTac, unpigmented, white; Taconics, Ejby, Denmark), DBA/1 (DBA/1JbomTac, hypopigmented, grey; Taconics), 12956 (129S6/SvEvTac, pigmented, brown; Taconics), and C57BL/6 (C57BL/6NTac, pigmented, black; Taconics) were purchased from commercial suppliers. In this paper, the three mouse strains with oculocutaneous albinism, CD1, BALB/c, and DBA/1, will be referred to as albino mice. $129 \mathrm{~S} 6$ and $\mathrm{C} 57 \mathrm{BL} / 6$ will be referred to as pigmented mice. At least five 12 - to 25 -week-old male mice ${ }^{10}$ of each strain were recorded and screened for ocular motor abnormalities. Some CD1 strains are known to show retinal degeneration. Even though this has not been reported for Crl:CD1(ICR) mice, ${ }^{11}$ we ruled out a possible Rd1 mutation by genotyping according to published procedures. ${ }^{12}$

\section{Surgery}

Reproducible recording of eye movements required restraint of the mouse heads by an aluminum plate attached to the skull. Animals were surgically prepared as described previously. ${ }^{10,13}$ Briefly, mice were anesthetized with a subcutaneous injection of ketamine $(1.7 \mu \mathrm{L} / \mathrm{g}) /$ xylazine $(0.2 \mu \mathrm{L} / \mathrm{g})$. After a sagittal incision of the scalp was made, connective tissue was removed from the skull and the exposed bone was air dried for at least 1 minute. A light curing, one component adhesive (iBond Total Etch; Heraeus Kulzer GmbH, Hanau, Germany) 

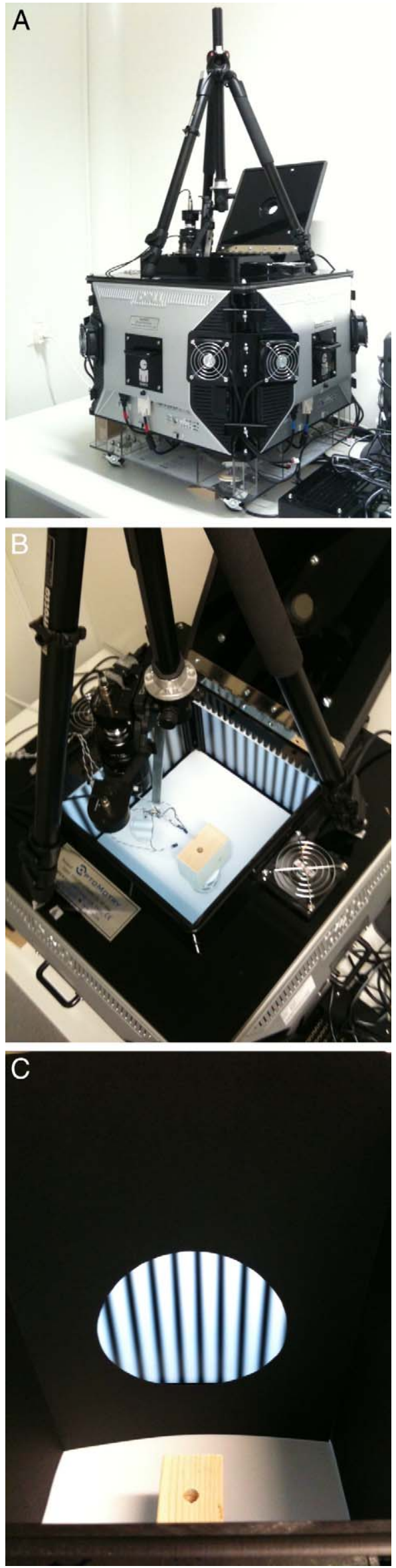

was applied to allow bonding between skull and dental cement (Charisma A1; Heraeus Kulzer GmbH). The latter formed the basis into which the aluminum plate was imbedded. It was then covered with a fluid composite (Tetric EvoFlow; Ivoclar Vivadent, Schaan, Lichtenstein) to ensure firm adhesion of the aluminum plate to the cement. All respective layers needed to be light cured with blue light (400-500 $\mathrm{nm}$ ) in order to form a hard layer (bluephase; Ivoclar Vivadent). Mice were allowed to recover from surgery for at least one week before eye movement recordings.

\section{Stimulus Setup}

A commercially available optomotor system (OptoMotry VR 1.7.7; CerebralMechanics Inc., Lethbridge, Alberta, Canada) was used to project different visual stimuli (Fig. 1). The system consists of four $20^{\prime}$ monitors creating a nearly cubic arena. Between the monitors, there are $5-\mathrm{cm}$ large edges without image in the corners (Fig. 1B). The restrained mouse was placed on an elevated platform (Fig. 1B) with the forehead in the center of that arena. The mouse faced the middle of one monitor with the body axis perpendicular to the front and back monitor, and parallel to the monitors on each side. The distance of the forehead to each monitor is $23.5 \mathrm{~cm}$. The OptoMotry stimulus system is designed such that the projected sine gratings get larger towards the corners of the arena as they compensate for the increasing viewing distance. This creates the illusion of a virtual cylinder around the mouse instead of the cubic geometry of the four screens. The presented visual stimuli were a projected black background, a projected white background, a stationary pattern of vertical sine gratings (spatial frequency $0.17 \mathrm{cyc} / \mathrm{deg}$, contrast $100 \%$ ), and a rotating sine grating eliciting an optokinetic response in temporonasal (tn) and nasotemporal (nt) direction relative to the recorded eye. The rotating visual stimulus had a velocity of $6.1 \mathrm{deg} / \mathrm{s}$. All visual stimuli were presented binocularly, however, eye movements were only recorded from the right eye. During recordings, the room was otherwise always dark.

Albino mice are known to have a chiasmatic projection error with retinal ganglion cells (RGC) from the inferotemporal retina being misdirected to the contralateral hemisphere. ${ }^{14,15}$ To selectively activate the temporal RGCs, which are misrouted in albino mice, visual stimuli were also displayed in the anterior visual field (aVF) only. For this purpose the monitors were masked with black cardboard except for a round window in front of the mouse (Fig. 1C). The window allowed binocular viewing of the stimuli in the aVF, $30^{\circ}$ to each side of the midline. (Window diameter $17.3 \mathrm{~cm}$ in $15-\mathrm{cm}$ distance from the mouse.) Except for the dark background, the exact same visual stimuli were presented in the full visual field (fVF) and aVF. The dark situation was not repeated with VF restriction, since it would again result in fVF darkness.

Illuminance of the white $\left[\mathrm{I}_{\max }=283 \operatorname{lux}(\mathrm{lx})\right]$ and dark $\left(\mathrm{I}_{\min }=1.4\right.$ lx) monitor was measured using a lux-meter (T-10; Konica Minolta Sensing, Inc., Osaka, Japan), which allowed calculation of sine grating contrast according to the Michelson formula $\left[\mathrm{C}=\left(\mathrm{I}_{\max }-\mathrm{I}_{\min }\right) /\left(\mathrm{I}_{\max }+\right.\right.$ $\left.\left.I_{\min }\right)\right]$. The calculated contrast was $99 \%$ and, for better readability, will be referred to as $100 \%$ in this paper. Average illuminance was $155 \mathrm{~lx}$ at the level of the mouse eye for both the stationary pattern and the optokinetic stimulus (OKS).

Figure 1. The experimental setup consisted of a commercially available optomotor system that allowed projection of visual stimuli on four monitors (A), and an infrared camera for eye tracking. The camera was placed on top of the OptoMotry system (A), with a hot mirror deviating the reflected infrared light from the eye to the camera (B). Visual stimuli were presented binocularly. However, only the right eye was tracked. The eye was illuminated with three infrared LEDs (B). For aVF stimulation, monitors were masked with black cardboard except for a round window in front of the mouse $(\mathbf{C})$. The window allowed binocular viewing of the stimuli in the aVF, $30^{\circ}$ to each side of the midline. 


\section{Eye Position Recording}

Eye position of the right eye, illuminated with three infrared LEDs, was recorded with infrared oculography at $120 \mathrm{~Hz}$ (ELT-200; ISCAN, Inc., Woburn, MA). The camera was placed on top of the OptoMotry system, with a hot mirror deviating the reflected infrared light from the eye to the camera (Fig. 1). The fact that albino mice have translucent irides made pupil tracking impossible in CD1 and BALB/c mice. Instead, an infrared absorbing marker (black iron oxide; H. Schmincke \& Co., Erkrath, Germany) was applied to the cornea after local anesthesia with oxybuprocaine. The infrared camera would then automatically track the marker. This method could not be applied to the other three strains since the marker would not sufficiently stand out from the pigmented iris to be recognized by the tracking function and software. This even applied to the DBA/1 mouse with its intermediate iris pigmentation. However, pupil and marker tracking has been compared earlier by van Alphen et al., ${ }^{16}$ and did not show significant differences with regard to recorded eye velocities. On the computer screen connected to the camera, the tracked eye was visualized by a zoomed live image.

While optimizing the experimental setup, all mice had gone through one or two training sessions before acquisition of the experimental quantitative data. During training sessions, ocular motor responses of up to 2 minutes per stimulus were observed. However, due to decreasing cooperation in some mice and the heating up of the OptoMotry system, the recording sessions were shortened for the experiment. A record of at least 10 seconds per stimulus in good tracking quality was considered sufficient. Usually 15 to 30 seconds, and for the stationary pattern, 30 to 60 seconds, were recorded, though. When a considerable build up of the ocular motor response was noted, the record was prolonged or restarted. The complete protocol of visual stimuli was recorded in one session for better comparability of ocular motor responses to various stimuli within one animal. If a session had to be stopped for some reason, the complete data set was repeated later. Loss of the corneal marker was one of the major reasons for postponing a session in CD1 and BALB/c mice. Some mice started to fight their restraint or to clean the whiskers, the latter especially being the case for DBA/1 mice. Often the attention of the mouse could be re-established with noise (by clapping hands). Even though blinking was not a general problem, it was still a reason for prolonged recording sessions in some of the mice. Depending on the cooperation of the mouse, the duration of each recording session was, thus, variable. Mice were, however, restrained for a maximum of approximately 30 minutes. In sum, pigmented mice had one to two training sessions, and one to two recording trials. Albino mice had two training sessions, and one to four recording trials. No more than one recording trial was done on one particular day.

\section{Data Analysis}

The horizontal pixel position $(512 \times 256$ pixel matrix $)$ of the corneal marker or pupil was transformed into a velocity signal by taking the first derivative (MATLAB; The MathWorks, Natick, MA). Measurement of the eye lid width (distance from medial to lateral canthus) in pixels on the screen and in millimeters in vivo (3.3-3.7 $\mathrm{mm}$, depending on the strain) as well as assumption of an eye radius of $1.67 \mathrm{~mm}^{17-20}$ allowed calibration of the system and calculation of velocities by a trigonometric function. Outliers with a change of greater than or equal to $0.5^{\circ}$ between two recorded pixel positions ( 0.008 second interval at $120 \mathrm{~Hz}$ ) were filtered applying a customized MATLAB function, and the remaining curve was smoothed with a Gaussian filter (low pass cutoff of $2.5 \mathrm{~Hz}$ ).

Recordings of 10 seconds duration were selected for quantitative analysis. The strongest responses with the least noise or blinking artifacts were chosen. Slow phase velocities in response to different visual stimuli were computed by ranking eye velocities of a single recording and calculating the median. This allowed computation of slow phase velocities without explicitly removing fast phases/saccades, which are not easily recognized in oscillating eye movements. Median eye velocities (MEV) in response to nonmoving visual stimuli were calculated as absolute values (statistical analysis on logarithmic data), whereas MEV in response to optokinetic visual stimuli were calculated in real numbers in order to preserve the information on slow phase direction. Eye movements in tn direction were assigned a negative value, eye movements in nt direction were assigned a positive value. OKR velocities of both directions were subtracted from each other $([-\mathrm{MEV}]-[+\mathrm{MEV}])$ resulting in a sum of the responses in both OKR directions. They were, thus, analyzed in one statistical test that was based on repeated measure ANOVA. Strain was the between-subject contrast, VF and visual stimulus were the within-subject contrasts. Differences between strains were analyzed by post hoc analysis with Bonferroni correction. All effects were considered as significant at $P$ less than or equal to 0.05 . Additional paired $t$-tests (level of significance adjusted for multiple testing) allowed comparisons of ocular motor responses to different visual stimuli within one strain. Significant $t$-test results are highlighted by asterisks (*) in the figures.

\section{Results}

VF $(P<0.001)$ and strain $(P<0.001)$ significantly influenced MEV and slow phase direction in OKR.

In the fVF situation, all strains had a slow phase direction following the direction of the OKS. Pigmented mice had smooth slow phases between fast phases, whereas albino strains showed oscillating slow phases, making it difficult to discern the slow phase direction. However, the slow phase direction can be deduced from the more easily recognizable fast phase direction (Fig. 2). Albino mice had a significantly lower MEV as compared with pigmented mice when the moving stimulus was presented to the fVF (Fig. 3, Table 1; univariate analysis, $P<0.001)$. Accordingly, their calculated mean gain values defined as slow phase velocity divided by stimulus velocity were only 0.1 to 0.4 [CD1: $0.4 \pm 0.1$ (tn direction) and $0.1 \pm 0.2$ (nt direction); BALB/c: $0.1 \pm 0.1$ (both tn and nt); DBA/1: $0.3 \pm 0.2$ (tn) and $0.2 \pm 0.03$ (nt)], whereas pigmented strains reached gain values of 0.5 to 0.7 [129S6: $0.7 \pm 0.1$ (both th and $\mathrm{nt}$ ); C57BL/6: $0.6 \pm 0.03$ (tn) and $0.5 \pm 0.1(\mathrm{nt})]$. The reason for the strongly asymmetric OKR response in CD1 mice is not clear and might warrant further investigation.

When the OKS was restricted to the aVF, all albino mice showed a significant change in their MEVs and a reversed OKR (i.e., an inversion of the slow phase direction). In contrast, pigmented mice showed only a reduction of MEV, but no change of direction (Figs. 2, 3, Table 1; univariate analysis, $P<0.001)$. As mentioned before, slow phase direction can be deduced from the more easily recognizable fast phase direction by visual inspection. Looking at the traces in Figure 2, interpretation of slow phase reversal in albino strains with VF restriction still seems challenging. However, slow phase reversal could be confirmed quantitatively. Figure 3 summarizes the OKR responses to both directions in the fVF situation (left side of the graph) and the aVF situation (right side of the graph). To allow inclusion of both OKR directions within one graph and, more importantly, within one statistical analysis, the MEV responses to both directions were combined to one $\triangle \mathrm{MEV}$ value per strain. Individual MEVs and the $\triangle \mathrm{MEV}$ for each strain and stimulus are given in Table 1 . MEV values of the second column (OKSnt, fVF) were subtracted from MEV values of the first column (OKStn, fVF), resulting in a negative $\triangle \mathrm{MEV}$ for all strains, which is represented in the third column $(\triangle \mathrm{MEV}$, fVF) and in Figure 3 (left side). In the aVF situation, albino mice had an inversion of the slow phase direction (in both tested stimulus directions). Thus, the algebraic signs of the MEV in the fourth (OKStn, aVF) and fifth column (OKSnt, aVF) are opposite between pigmented and albino mice, resulting in 
Full Visual Field OKR

CD1

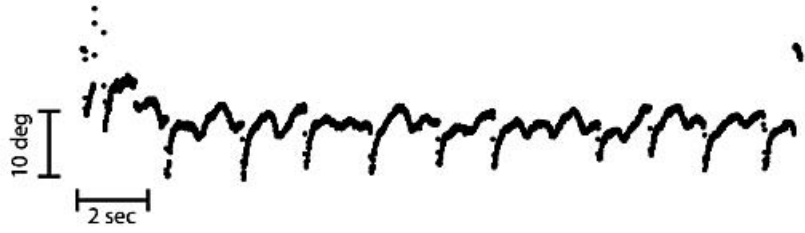

$\mathrm{BALB} / \mathrm{c}$

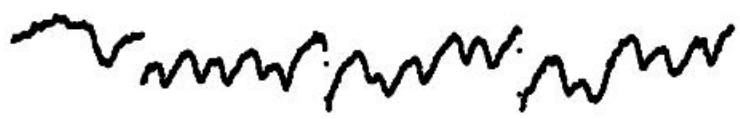

$\mathrm{DBA} / 1$

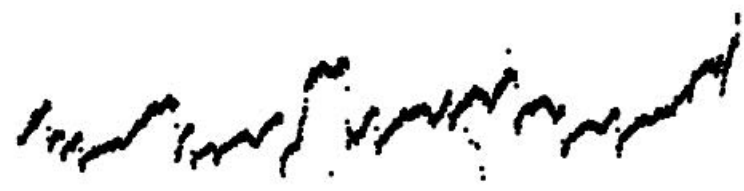

12956

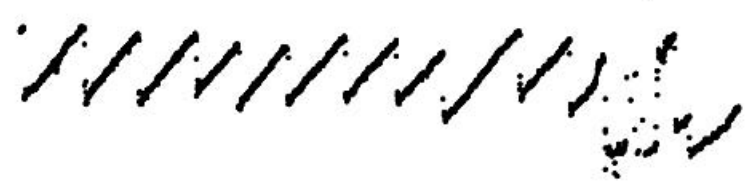

C57BL/6

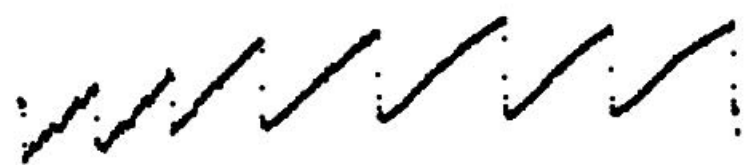

Anterior Visual Field OKR

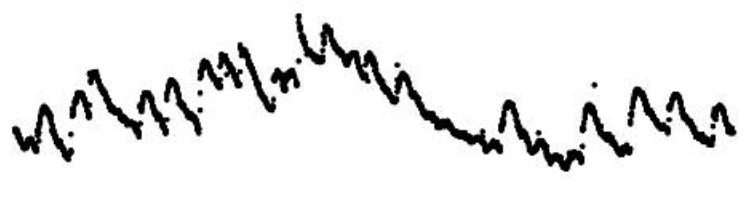

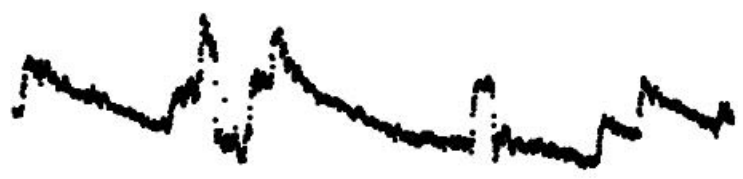

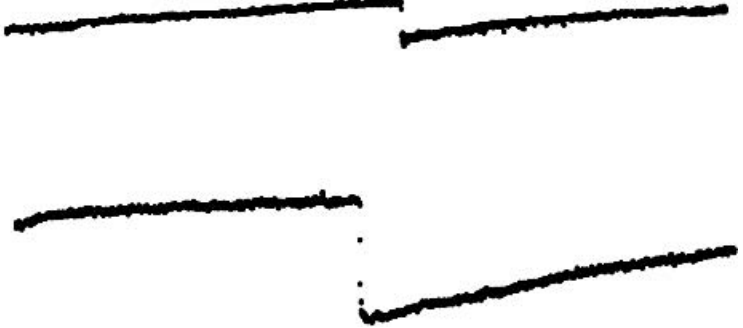

FIGURE 2. Optokinetic response. An OKS (direction: nasal to temporal with respect to the recorded right eye; velocity: $6.1 \mathrm{deg} / \mathrm{s}$; spatial frequency: $0.17 \mathrm{cyc} / \mathrm{deg}$; contrast: $100 \%$ ) was presented to the fVF (left column) or the aVF (right column). Eye movements were recorded from right eyes of the five mouse strains and presented as horizontal pupil position ( $y$-axis) over time ( $x$-axis). A lower position on the $y$-axis indicates a more nasal pupil position, whereas a higher position on the $y$-axis indicates a more temporal pupil position. Scaling is identical for all traces shown and indicated for CD1 after stimulation of the fVF. With a fVF OKS, the slow phase followed the direction of the rotating grating in all strains. Albino strains showed some superimposed oscillations. aVF stimulation resulted in reversal of the OKR in albino mice (i.e., the slow phase direction was opposite to the stimulus direction). In pigmented mice, the OKR was reduced with VF restriction, but the direction remained unchanged. Representative recordings of single mice are shown. Note, that in albino mice the degree of the nystagmus and the waveforms varied considerably over time.

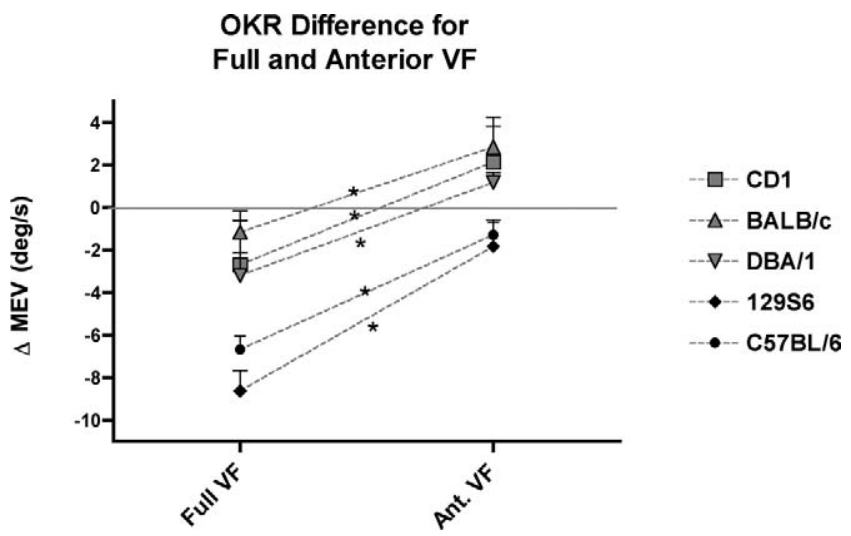

Figure 3. Optokinetic response. The difference of the OKR MEV $(\Delta$ MEV) between th direction (assigned a negative value) and nt direction (assigned a positive value) was calculated and plotted (mean $\pm \mathrm{SD} ; N=$ 5-6 per strain) for fVF and aVF stimulation. All strains had a significantly changing OKR response with VF restriction $\left({ }^{*} P \leq 0.05\right)$. Note that $\Delta$ MEVs in albino strains were negative for fVF stimulation and positive for aVF stimulation indicating a reversal of the OKR direction after presentation of the stimulus to the aVF. negative $\triangle \mathrm{MEV}$ in pigmented mice and positive $\triangle \mathrm{MEV}$ in albino mice when subtracting the fifth column from the fourth column. This is represented in the sixth column $(\triangle \mathrm{MEV}, \mathrm{aVF})$ and in Figure 3 (right side).

For both the fVF and restricted VF situation, no significant differences of the OKR response were recorded between strains within the albino or within the pigmented group.

Stationary visual stimuli (uniformly white or sine gratings) were used to record spontaneous eye movements. Here, VF ( $P$ $<0.003)$, visual stimulus $(P<0.001)$, and strain $(P<0.001)$ had a significant effect on MEV (Figs. 4, 5, Table 2). In addition, the data revealed a significant interaction between visual stimulus and strain $(P<0.001)$ indicating strain specific differences of the ocular motor response to stimulus changes.

Generally, albino mice had significantly higher MEVs (or greater ocular motor instability) compared with pigmented mice under stationary experimental conditions (Figs. 4, 5, Table 2) except for the following: with a white background, the difference in MEV between C57BL/6 and BALB/c in the full field situation, and between $\mathrm{C} 57 \mathrm{BL} / 6$ and BALB/C or DBA/ 1 in the restricted field situation were not significant (Table 2).

To analyze the influence of a VF change on ocular motor stability, the MEV in response to visual stimuli in the fVF and the aVF were compared. Whereas eye velocities did not change 
TaBle 1. Median Eye Velocity of the Optokinetic Response

\begin{tabular}{lcccrrr}
\hline Strain $(\boldsymbol{n})$ & OKStn (fVF) & OKSnt (fVF) & MMEV (fVF) & OKStn (aVF) & OKSnt (aVF) & $\Delta$ MEV (aVF) \\
\hline CD1 (6) & $-2.2 \pm 0.8$ & $0.5 \pm 1.3$ & $-2.7 \pm 2.1$ & $0.7 \pm 0.4$ & $-1.4 \pm 1.9$ & $2.1 \pm 2.1$ \\
BALB/c (6) & $-0.5 \pm 0.5$ & $0.7 \pm 0.8$ & $-1.2 \pm 1.0$ & $1.7 \pm 0.7$ & $-1.2 \pm 0.5$ & $2.8 \pm 1.0$ \\
DBA/1 (5) & $-1.9 \pm 1.0$ & $1.3 \pm 0.2$ & $-3.2 \pm 1.1$ & $0.3 \pm 0.1$ & $-0.9 \pm 0.4$ & $1.2 \pm 0.5$ \\
129S6 (6) & $-4.1 \pm 0.6$ & $4.5 \pm 0.4$ & $-8.6 \pm 1.0$ & $-1.2 \pm 1.1$ & $0.6 \pm 0.3$ & $-1.8 \pm 1.3$ \\
C57BL/6 (6) & $-3.4 \pm 0.2$ & $3.3 \pm 0.8$ & $-6.7 \pm 0.6$ & $-0.8 \pm 0.7$ & $0.5 \pm 0.3$ & $-1.3 \pm 0.6$ \\
Statistics & & & $P<0.001$ & & $P<0.001$
\end{tabular}

MEV (deg/s; mean $\pm \mathrm{SD} ; N=5-6$ per strain as indicated) of the OKR to an OKS in the fVF or aVF moving in a th or nt direction. $\triangle \mathrm{MEV}$ corresponds to the difference between the MEV in the two directions $[\triangle \mathrm{MEV}=\mathrm{MEV}(\mathrm{OKStn})-\mathrm{MEV}(\mathrm{OKSnt})]$. Statistical analysis is based on the latter. Univariate analysis indicated significant MEV differences between strains. MEV of all albino strains were significantly different from MEV of pigmented strains (post hoc analysis).

in any strain when a white stimulus was presented (Fig. 5A), ocular motor instability significantly increased in albino strains in response to a pattern background when the VF was restricted $(P<0.001$ with significant interaction of $\mathrm{VF}$ and strain, $P<0.001$ ) (Fig. 5B). In individual strains, the changing ocular motor response with regard to pattern stimulation in the fVF and aVF was further analyzed using paired $t$-tests with correction of the significance level for multiple testing (four $t$ tests per strain, i.e., one $t$-test per panel A-D in Fig. 4). As a consequence of this correction, only a $P$ value of greater than or equal to $0.0125(0.05 / 4)$ could be considered significant.

\section{Full Visual Field Pattern}

CD1

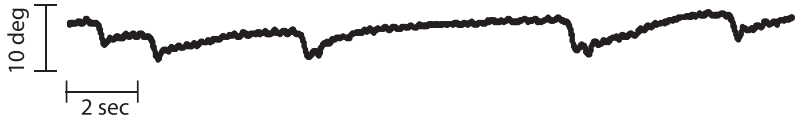

$\mathrm{BALB} / \mathrm{C}$

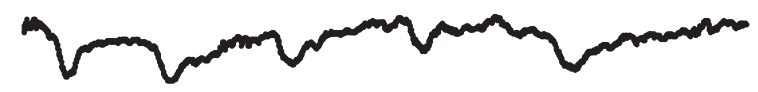

$\mathrm{DBA} / 1$

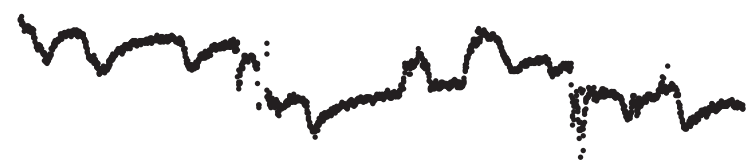

12956

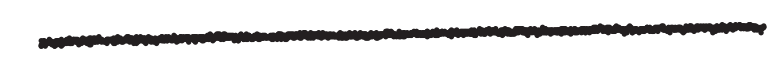

This 4-fold reduction of the significance level resulted in loss of significance of the observed VF influence in albino strains.

To analyze stimulus dependency of the ocular motor stability, MEVs in response to a white background were compared with a pattern background in the same VF (Figs. 5C, 5D). In albino mice, MEV and, thus, ocular motor instability tended to increase with the addition of a pattern to the background, while in pigmented mice, MEV remained stable or even decreased. The effect of the stimulus on the ocular motor response in albino mice reached statistical significance only in the restricted VF situation (Fig. 5D; $P<0.001$; with significant interaction of stimulus and strain, $P<$

\section{Anterior Visual Field Pattern}
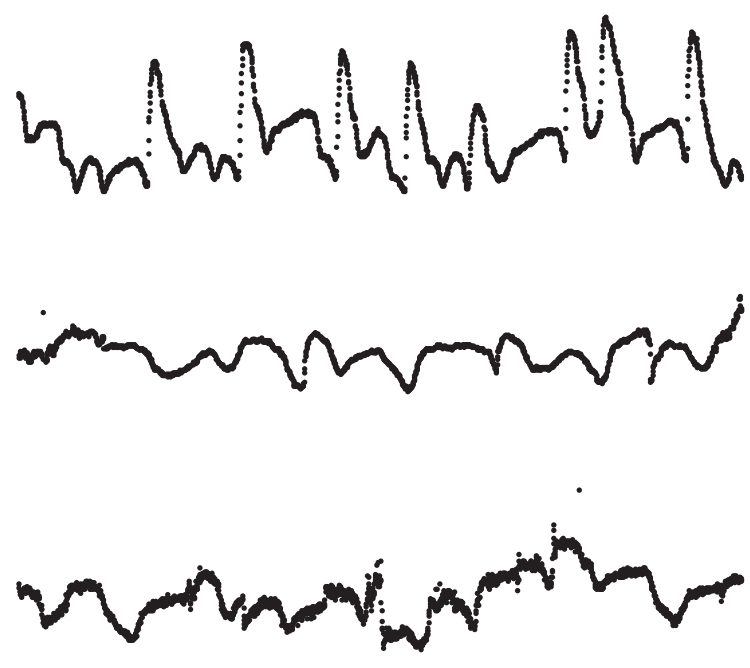

(1)

C57BL/6

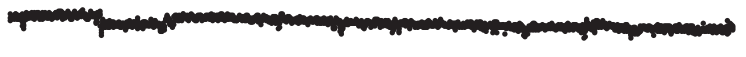

Figure 4. Spontaneous eye movements. A stationary pattern stimulus (spatial frequency: $0.17 \mathrm{cyc} / \mathrm{deg}$; contrast: $100 \%$ ) was presented to the fVF (left column) or the aVF (right column). Spontaneous eye movements were recorded from right eyes of the five mouse strains and presented as horizontal pupil position ( $y$-axis) over time ( $x$-axis). A lower position on the $y$-axis indicates a more nasal pupil position whereas a higher position on the $y$-axis indicates a more temporal pupil position. Scaling is identical for all traces as shown and indicated for CD1 after stimulation of the fVF. With a pattern stimulus, albino mice showed vigorous spontaneous oscillations, which further increased with VF restriction. In pigmented mice, only slowly drifting eye movements were present for both fVF and aVF stimulation. 

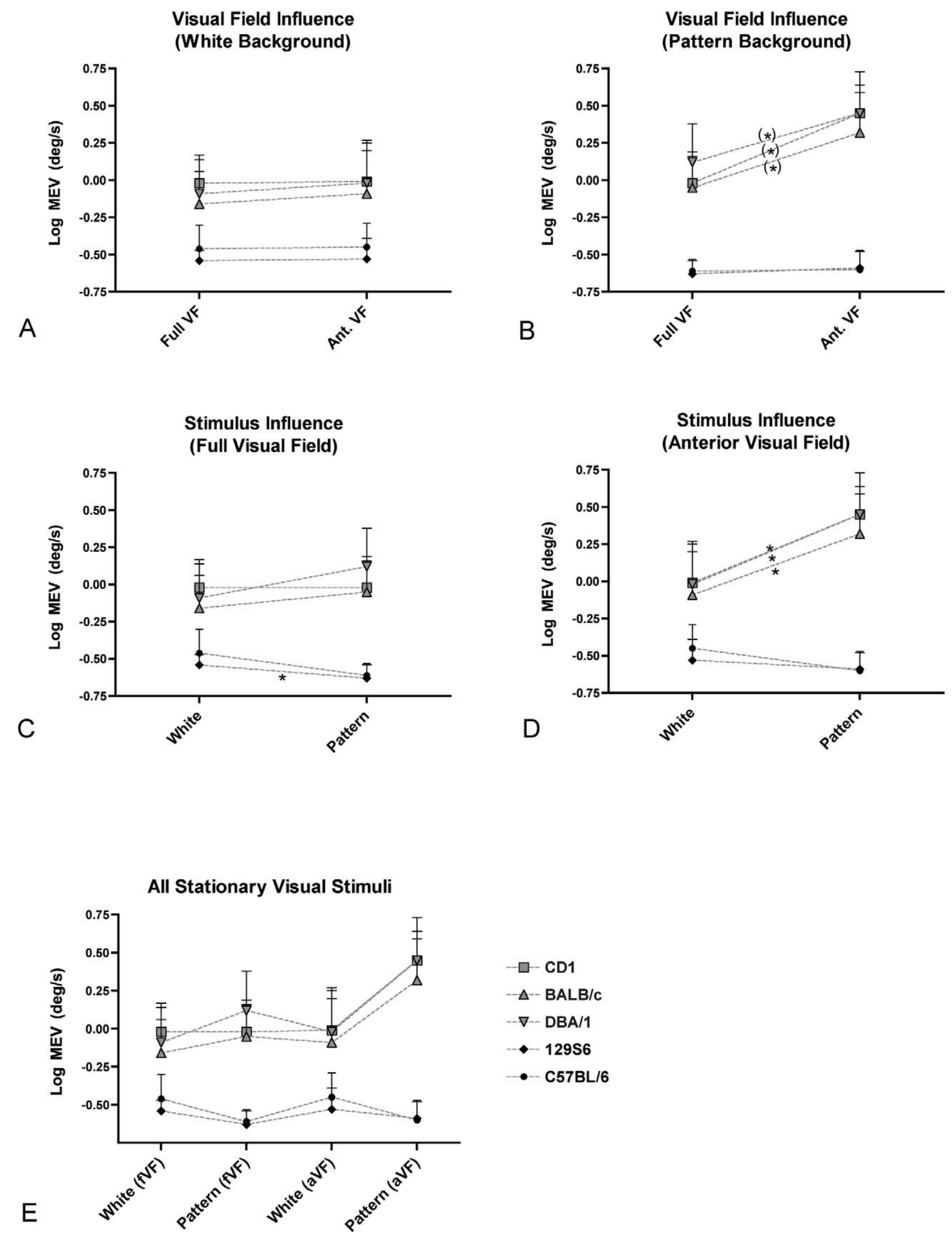

FIGURE 5. Spontaneous eye movements. Logarithmic MEV (mean $\pm \mathrm{SD} ; N=5-6$ per strain) of spontaneous eye movements with varying stationary visual stimuli in the fVF or aVF. Asterisks (*) indicate significant MEV changes within one strain. (A) VF restriction of an unstructured white background induced no significant change in MEVs. (B) VF restriction of a structured background induced a higher ocular motor instability in albino mice (VF dependency of ocular motor stability). However, significance was lost with correction for multiple testing, indicated with asterisks in brackets (0.05 $\geq P \geq 0.0125)$. In pigmented mice, VF restriction had no effect on ocular motor stability. (C) The 129 S6 strain showed a significant 
MEV reduction with a pattern stimulus in the aVF as compared with a white background stimulus (stabilizing effect of a structured background). (D) In albino mice, ocular motor instability significantly $(P \leq 0.0125)$ increased with pattern stimulation of the aVF (destabilizing effect). The stabilizing effect of the pattern was nonsignificant in pigmented mice. (E) Albino strains had significantly higher MEVs under all experimental conditions.

0.001). This interaction and the destabilizing effect of a stationary pattern in the aVF were confirmed in albino mice using paired $t$-tests $(P \leq 0.0125)$. Our results suggested an opposite, stabilizing effect of the pattern stimulus in pigmented strains. However, this was only significant for the 129S6 strain in the fVF situation (Fig. 5C). A summary of the MEVs for all strains in response to all stationary stimuli is given in Figure 5E.

To determine whether spontaneous nystagmus depends on visual input, we measured eye movements in darkness. With projection of a black background, albino mice had subtle spontaneous oscillations, whereas pigmented mice seemed to have stable eye positions apart from occasional saccades (arrowheads, Fig. 6). However, these measurements were not included in the analysis because the physiologic pupil dilation in darkness created too much noise for pupil tracking and resulted in unreliable data in the three pupil tracked strains (DBA/1, 129S6, C57BL/6). An exceptionally good recording of a C57BL/6 mouse is shown in Figure 6.

\section{Discussion}

Melanin synthesis disorders, such as oculocutaneous albinism, predispose to visual system abnormalities affecting the retina (foveal hypoplasia ${ }^{21-23}$ ) and retinofugal projections, ${ }^{24-31}$ which lead to reduced visual acuity, loss of binocular vision, and INS in humans. ${ }^{32}$ Melanin is mainly expressed in melanocytes (skin, iris, choroid) and in the retinal pigment epithelium (RPE). ${ }^{33}$ Reduced melanin content in the RPE of albinotic mice was correlated to a roughly $30 \%$ reduction in the number of rod photoreceptors, ${ }^{34}$ to a prolonged cell cycle of RGCs in rats during neurogenesis, ${ }^{35}$ to an underdeveloped central retina in several mammals, ${ }^{36-39}$ and to a reduction of uncrossed retinofugal projections in mouse, ${ }^{14,15,40-47}$ rat, ${ }^{48,49}$ rabbit, ${ }^{50}$ cat, ${ }^{51}$ ferret, ${ }^{52,53}$ and tiger. $^{54}$ The percentage of ipsilateral projections in $\mathrm{BALB} / \mathrm{C}$ and $\mathrm{CD} 1$ mice has been quantified to $1.8 \%$ as compared with the normal $2.8 \%$ in $\mathrm{BL} / 6$ mice. ${ }^{45}$

CD1 and BALB/c mice carry a missense mutation in Tyr (tyrosinase), which leads to a cysteine to serine exchange at position 103 of the protein [TYR, C103S, c (albino) locus ${ }^{55}$ ], a key enzyme in melanin synthesis. ${ }^{33} \mathrm{DBA} / 1$ mice express a mutant form of the tyrosinase associated protein (TYRP1b) involved in a downstream enzymatic step during melanin synthesis $^{56}$ and in stabilization of the tyrosinase. ${ }^{57}$ The functional connection of these two proteins may explain the similarities we found in the ocular motor phenotype among the three albino mouse strains.
While recordings were straightforward in pigmented strains, especially in 129S6, data acquisition was much more challenging in albino strains due to eventual loss of the corneal marker, on the one hand, and behavioral differences with increased agitation of the albino mice on the other hand. Nevertheless, recordings finally resulted in analyzable data for all animals. The fraction of usable data per session in pigmented mice was approximately $90 \%$, while it was only approximately $40 \%$ in the albino strains, which generally had longer sessions and more session break offs. Alertness was difficult to judge in all five strains. Still, we are confident that the results reflect the response to the different testing paradigms, since our findings were consistent among the individual mice of a particular strain.

Assuming that spontaneous oscillations are related to the anomalous optokinetic performance in albino mice, OKR results will be discussed first, followed by discussion of spontaneous oscillations.

\section{Optokinetic Response}

Pigmented strains had a robust OKR to a fVF stimulus. The significantly weakened OKR in response to a restricted VF stimulus (anterior field) is in line with earlier findings. ${ }^{58,59}$ Despite superimposed oscillations increasing the calculated velocity signal, the median OKR velocities of albino mice were significantly lower during fVF stimulation as compared with pigmented mice. This may point either to an afferent or efferent visual system dysfunction, ${ }^{60}$ or to a combination of both. The visual gain might be reduced due to an altered retinal anatomy affecting visual acuity or due to the projection error inducing a conflicting visual input. ${ }^{61}$ On the other hand, a miscalibrated efferent ocular motor system itself might limit the ocular motor response as well. ${ }^{62}$

When albino mice were presented with an OKS in the aVF only, the OKR response was reversed as it has been reported earlier by Mangini et al. ${ }^{58}$ OKR data reported by Mangini et al., as well as our own OKR data, were tested at a stimulus velocity of $6.0 \mathrm{deg} / \mathrm{s}$ and $6.1 \mathrm{deg} / \mathrm{s}$, respectively. Reversal of the OKR might, however, depend on stimulus velocity. This possible velocity relationship on the OKR response might warrant further investigation. In contrast to Mangini and coworkers, ${ }^{58}$ we additionally detected a clear OKR in response to a stimulus in the $\mathrm{fVF}$ in a majority of albino mice (Figs. 2, 3), and report spontaneous oscillations (Figs. 4, 5) in these mice. Since Mangini manually analyzed videotaped eye recordings, the sensitivity of the system may not have been sufficient to reliably discover these movements. The automated eye

Table 2. Median Eye Velocity of Spontaneous Eye Movements

\begin{tabular}{lcccr}
\hline Strain $(\boldsymbol{n})$ & White (fVF) & Pattern (fVF) & White (aVF) & Pattern (aVF) \\
\hline CD1 (6) & $1.0 \pm 0.4$ & $1.0 \pm 0.4$ & $1.2 \pm 1.1$ & $3.4 \pm 2.4$ \\
BALB/c (6) & $0.8 \pm 0.4$ & $1.0 \pm 0.6$ & $1.1 \pm 1.3$ & $2.6 \pm 1.6$ \\
DBA/1 (5) & $0.9 \pm 0.6$ & $1.5 \pm 1.1$ & $1.1 \pm 0.5$ & $2.9 \pm 0.9$ \\
129S6 (6) & $0.3 \pm 0.0$ & $0.2 \pm 0.0$ & $0.3 \pm 0.1$ & $0.3 \pm 0.1$ \\
C57BL/6 (6) & $0.4 \pm 0.1$ & $0.2 \pm 0.0$ & $0.4 \pm 0.2$ & $0.3 \pm 0.1$ \\
Statistics & $P<0.001$ & $P<0.001$ & $(\mathrm{BALB} / \mathrm{c}-\mathrm{BL} / 6: \mathrm{ns})(\mathrm{DBA} / 1-\mathrm{BL} / 6: \mathrm{ns})$ & $P<0.001$ \\
& $(\mathrm{BALB} / \mathrm{c}-\mathrm{BL} / 6: \mathrm{ns})$ & &
\end{tabular}

Median eye velocities MEV (deg/s; mean $\pm \mathrm{SD} ; N=5-6$ per strain as indicated) of spontaneous eye movements for varying stationary visual stimuli in the fVF or aVF. Univariate analysis indicated significant MEV differences between strains. Apart from the exceptions mentioned in the table (ns = nonsignificant), MEV of all albino strains were significantly different from MEV in pigmented strains (post hoc analysis). 

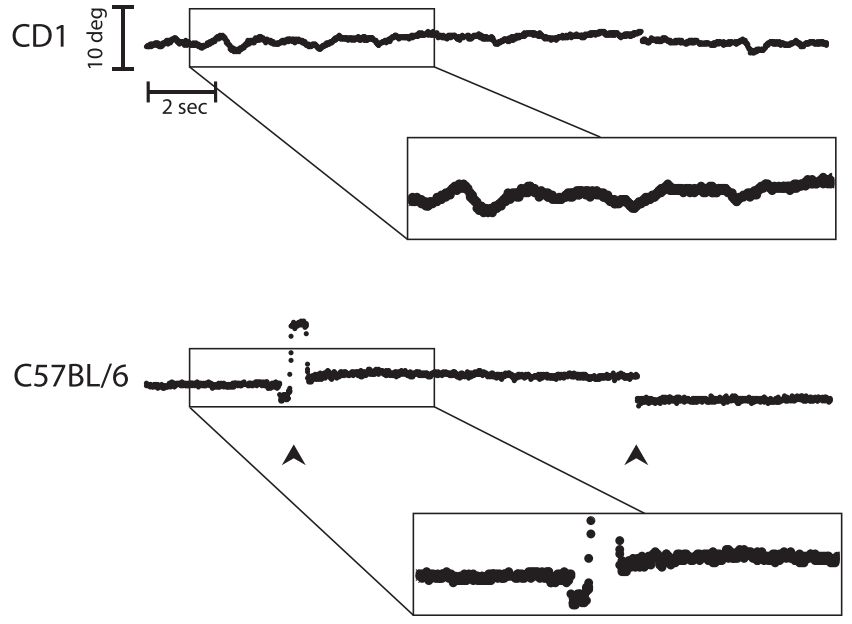

Figure 6. Spontaneous eye movements in the dark. Spontaneous eye movements were recorded from right eyes and presented as horizontal pupil position ( $y$-axis) over time ( $x$-axis). A lower position on the $y$-axis indicates a more nasal pupil position, whereas a higher position on the $y$-axis indicates a more temporal pupil position. Scaling is identical for both strains and as indicated for CD1. For better comparison with other stimulus conditions, scaling is identical for Figures 2, 4, and 6. Albino mice had subtle spontaneous oscillations in the dark indicating that the efferent visual system might be involved in the pathogenesis of spontaneous nystagmus as well. Pigmented mice seemed to have stable eye positions apart from occasional spontaneous saccades (arrowheads). Zoomed insets show those subtle spontaneous oscillations in a CD1 mouse as compared with stable eye positions with a saccade in a C57BL/6 mouse at higher resolution. Since physiologic pupil dilation in darkness generally caused increased background noise during pupil tracking, results for the three pupil tracked strains (DBA/1, 129S6, C57BL/6) were generally unreliable for statistic evaluation. An exceptionally good recording of a $\mathrm{C} 57 \mathrm{BL} / 6$ mouse is shown as an example.

tracking system used here might provide superior sensitivity and allow better quantification of oscillations.

The reversed OKR response may be based on the projection error in albinos ${ }^{61}$ resulting in destabilizing positive feedback in response to retinal slip. This hypothesis is supported by mathematical models ${ }^{60,63}$ and by recent experimental findings in belladonna (bel) zebrafish mutants, which display a reversed OKR that perfectly correlates with purely ipsilateral retinotectal projections (instead of the normal complete crossing of RGCs in wild type zebrafish). ${ }^{63-65}$

Due to differing views on eye movement analysis, Jacobs and Dell'Osso ${ }^{62}$ doubt the true nature of reversed OKR. Nevertheless, it has been described by several authors. $6,66-68$ Even though it is not present in all patients with INS, reversed OKR is considered a common pathognomonic finding in INS. ${ }^{7}$ Except for one study, ${ }^{67}$ reversed OKR was mainly investigated with fVF stimulation. ${ }^{6,66,68}$ Collewijn et al. $^{67}$ additionally analyzed the OKR response with VF restriction (to the temporal or nasal VF) in subjects with OKR inversion, but did not find any influence of the VF on the OKR response. These findings in humans contrast with our own OKR data in albino mice. Mice normally have $2.8 \%$ ipsilateral retinofugal projections ${ }^{45}$ compared with $47 \%$ ipsilateral projections in humans. ${ }^{69}$ Since mice have a rather small amount of normal ipsilateral projections, the misrouted fibers in albino mice only represent a very small proportion of the total projections. This might explain the fact that specific stimulation of the temporal retina is necessary to induce reversed OKR in mice.

\section{Spontaneous Oscillations}

Spontaneous oscillations have been analyzed in the albino rabbit. ${ }^{61}$ They have also been observed in the albino mouse ${ }^{70}$ and the albino rat $^{71,72}$; however, such oscillations have not been properly investigated in rodents.

Here, we present data clearly showing spontaneous nystagmus, specifically jerks and oscillations, in three albino mouse strains. In contrast, ocular positions were nearly stable in pigmented mice. Spontaneous MEVs were significantly greater in albino mice and showed a significant stimulus dependency for ocular motor instability in the aVF. The fact that MEV markedly increased with a pattern background compared with a white background supports the positive feedback hypothesis in albinos, since spontaneous eye movements induce retinal slip in a structured environment, whereas in a uniform environment they do not. Conversely, the negative feedback system of pigmented mice seemed to induce a stabilization of gaze, which was, however, only significant in one strain (129S6, fVF stimulation). There was a trend for VF dependency of ocular motor stability in albino strains (with pattern background). This might reach significance with the analysis of more animals per group and could be explained by the projection error of the corresponding retina. There was no indication of a similar effect of $\mathrm{VF}$ restriction in pigmented mice. The increasingly slow phase velocity of jerk waveforms was not a predominant feature in our albino mice, which might also relate to the fact that mice are afoveate species. In sum, our data support the idea of a dominant problem in the afferent pathways in the context of INS. However, the fact that spontaneous nystagmus was also detected in darkness, albeit with a smaller amplitude (Fig. 6), may implicate the efferent visual system in the pathogenesis of INS as well, possibly as a result of central motor adaptation to the aberrant visual input.

The effect of ocular motor instability on visual performance may be tested in behavioral studies. Strong differences have been reported for albino mice in such tests, ${ }^{73-75}$ with BALB/c mice generally performing poorly. However, our results suggest that even BALB/c mice do have considerable vision, and, like CD1 and DBA/1 mice, react to stimuli in a consistent, albeit abnormal way. Variable performances in behavioral vision tests have also been reported in DBA/2J mice, ${ }^{73,74,76,77}$ a commonly used glaucoma mouse model. DBA/2J mice carry a digenic mutation in Tyrp1b and Gpnmb (Glycoprotein nonmetastatic melanoma protein $\mathrm{B}$ ) causing pigmentary dispersion syndrome and pigmentary glaucoma leading to RGC degeneration. ${ }^{78,79}$ When interpreting optomotor test results, it has to be kept in mind that the Tyrp1b mutation might influence ocular motor phenotype in the same way as it likely influences the investigated DBA/1 strain. Hence, more detailed studies are needed to quantify the visual capacities of this strain and how they are affected by nystagmus.

Current hypotheses on the etiology of INS include structural defects (i.e., misprojection ${ }^{65}$ ) motor defects, ${ }^{80}$ impaired sensorimotor integration, ${ }^{81}$ and miscalibration of the visual system during development due to sensory disorders. ${ }^{62,82}$ Interestingly, dark rearing has been shown to affect ocular motor function (reduced gain) in mice, suggesting that visual input might be needed for normal development of the ocular motor system. ${ }^{83}$

Recently, mutations in the FERM domain containing 7 (FRMD7) gene have been identified in X-linked INS, ${ }^{84,85}$ which offers a completely new approach to INS related research. The function of FRMD7 is still unclear, but seems related to neuronal development. ${ }^{85,86}$

Still, mechanisms underlying INS remain incompletely understood, partly due to the absence of an easily accessible and established mammalian animal model. Although INS has 
already been reported in the achiasmatic mutant Belgian sheepdog, ${ }^{87,88}$ and RPE65-deficient canines, ${ }^{89}$ investigations in these animals are limited due to high costs and the unfeasibility of high throughput experiments. Other proposed animal models appeared to have induced latent, 90,91 or acquired nystagmus, ${ }^{92}$ which may not be comparable to INS. More recently, the achiasmatic zebrafish belladonna mutant, a teleost, has been established as a valuable animal model for INS. ${ }^{65}$ Whereas the use of zebrafish has many advantages, like high throughput experiments and faster genetic manipulations, it seems necessary to establish a mammalian model for evaluation of generalizability of zebrafish data. Modern eye tracking systems now provide considerably enhanced research possibilities in the field. ${ }^{16,93}$ Based on our results, we clearly demonstrate that albino mice show ocular motor abnormalities and spontaneous nystagmus. Thus, they could complement the zebrafish as a promising new mammalian model to study mechanisms of INS. As an intermediate species between the lower vertebrate zebrafish and humans, mice not only provide us with the power of mouse genetics, but also may enable us to investigate the role of the cortical visual pathways in INS, and to find a common mechanism for INS across species. In addition, mice might also provide the opportunity to test pharmacological approaches to developing noninvasive therapies for INS.

\section{Acknowledgments}

The authors thank Klara Landau, MD, David Margolis, PhD, Marijana Samardzija, PhD, Sarah Willcox, MD, Marco Penner, technician, and Konrad Weber, MD, for their contribution to this work.

\section{References}

1. Sarvananthan N, Surendran M, Roberts EO, et al. The prevalence of nystagmus: the Leicestershire nystagmus survey. Invest Ophthalmol Vis Sci. 2009;50:5201-5206.

2. Forssman B, Ringner B. Prevalence and inheritance of congenital nystagmus in a Swedish population. Ann Hum Genet. 1971;35:139-147.

3. Gresty M, Page N, Barratt H. The differential diagnosis of congenital nystagmus. J Neurol Neurosurg Psychiatry. 1984; 47:936-942.

4. Maybodi M. Infantile-onset nystagmus. Curr Opin Ophthalmol. 2003;14:276-285.

5. Dell'Osso LF, Daroff RB. Congenital nystagmus waveforms and foveation strategy. Doc Ophthalmol. 1975;39:155-182.

6. Halmagyi GM, Gresty MA, Leech J. Reversed optokinetic nystagmus $(\mathrm{OKN})$ : mechanism and clinical significance. Ann Neurol. 1980;7:429-435.

7. Thurtell MJ, Leigh RJ. Nystagmus and saccadic intrusions. Handb Clin Neurol. 2011;102:333-378.

8. Lorenz B, Gampe E. Analysis of 180 patients with sensory defect nystagmus (SDN) and congenital idiopathic nystagmus (CIN) [in German]. Klin Monbl Augenbeilkd. 2001;218:3-12.

9. Weiss AH, Biersdorf WR. Visual sensory disorders in congenital nystagmus. Ophthalmology. 1989;96:517-523.

10. van Alphen B, Winkelman BH, Frens MA. Age- and sex-related differences in contrast sensitivity in $\mathrm{C} 57 \mathrm{BL} / 6$ mice. Invest Ophthalmol Vis Sci. 2009;50:2451-2458.

11. Serfilippi LM, Pallman DR, Gruebbel MM, Kern TJ, Spainhour CB. Assessment of retinal degeneration in outbred albino mice. Comp Med. 2004;54:69-76.

12. Samardzija M, Wenzel A, Thiersch M, Frigg R, Reme C, Grimm C. Caspase-1 ablation protects photoreceptors in a model of autosomal dominant retinitis pigmentosa. Invest Ophthalmol Vis Sci. 2006; 47:5181-5190.

13. Lutcke $\mathrm{H}$, Murayama M, Hahn $\mathrm{T}$, et al. Optical recording of neuronal activity with a genetically-encoded calcium indicator in anesthetized and freely moving mice. Front Neural Circuits. 2010;4:9.

14. Drager UC, Olsen JF. Origins of crossed and uncrossed retinal projections in pigmented and albino mice. J Comp Neurol. 1980;191:383-412.

15. Balkema GW, Drager UC. Origins of uncrossed retinofugal projections in normal and hypopigmented mice. Vis Neurosci. 1990;4:595-604.

16. van Alphen B, Winkelman BH, Frens MA. Three-dimensional optokinetic eye movements in the C57BL/6J mouse. Invest Ophthalmol Vis Sci. 2010;51:623-630.

17. Chalupa LM, Williams RW. Eye, Retina, and Visual System of the Mouse. Cambridge, MA: MIT Press; 2008:74.

18. Schmucker C, Schaeffel F. A paraxial schematic eye model for the growing C57BL/6 mouse. Vision Res. 2004;44:1857-1867.

19. Remtulla S, Hallett PE. A schematic eye for the mouse, and comparisons with the rat. Vision Res. 1985;25:21-31.

20. Shupe JM, Kristan DM, Austad SN, Stenkamp DL. The eye of the laboratory mouse remains anatomically adapted for natural conditions. Brain Behav Evol. 2006;67:39-52.

21. Elschnig A. Zur Anatomie des menschlichen Albinoauges. Graefe's Arch Clin Exp Ophthalmol. 1913;84:401-419.

22. Naumann GO, Lerche W, Schroeder W. Foveolar aplasia in tyrosinase-positive oculocutaneous albinisim (author's transl) [in German]. Albrecht Von Graefes Arch Klin Exp Ophthalmol. 1976;200:39-50.

23. Kelly JP, Weiss AH. Topographical retinal function in oculocutaneous albinism. Am J Ophthalmol. 2006;141:1156-1158.

24. Creel D, Witkop CJJ, King RA. Asymmetric visually evoked potentials in human albinos: evidence for visual system anomalies. Invest Ophthalmol. 1974;13:430-440.

25. Guillery RW, Okoro AN, Witkop CJJ. Abnormal visual pathways in the brain of a human albino. Brain Res. 1975;96:373-377.

26. Morland AB, Hoffmann MB, Neveu M, Holder GE. Abnormal visual projection in a human albino studied with functional magnetic resonance imaging and visual evoked potentials. $J$ Neurol Neurosurg Psychiatry. 2002;72:523-526.

27. Pott JW, Jansonius NM, Kooijman AC. Chiasmal coefficient of flash and pattern visual evoked potentials for detection of chiasmal misrouting in albinism. Doc Ophthalmol. 2003;106: 137-143.

28. Schmitz B, Krick C, Kasmann-Kellner B. Morphology of the optic chiasm in albinism [in German]. Ophthalmologe. 2007; 104:662-665.

29. von dem Hagen EA, Hoffmann MB, Morland AB. Identifying human albinism: a comparison of VEP and fMRI. Invest Ophthalmol Vis Sci. 2008;49:238-249.

30. von dem Hagen EA, Houston GC, Hoffmann MB, Morland AB. Pigmentation predicts the shift in the line of decussation in humans with albinism. Eur J Neurosci. 2007;25:503-511.

31. Hoffmann MB, Lorenz B, Morland AB, Schmidtborn LC. Misrouting of the optic nerves in albinism: estimation of the extent with visual evoked potentials. Invest Ophthalmol Vis Sci. 2005;46:3892-3898.

32. Oetting WS, King RA. Molecular basis of albinism: mutations and polymorphisms of pigmentation genes associated with albinism. Hum Mutat. 1999;13:99-115.

33. Ray K, Chaki M, Sengupta M. Tyrosinase and ocular diseases: some novel thoughts on the molecular basis of oculocutaneous albinism type 1. Prog Retin Eye Res. 2007;26:323-358.

34. Jeffery G, Brem G, Montoliu L. Correction of retinal abnormalities found in albinism by introduction of a 
functional tyrosinase gene in transgenic mice and rabbits. Brain Res Dev Brain Res. 1997;99:95-102.

35. Ilia M, Jeffery G. Delayed neurogenesis in the albino retina: evidence of a role for melanin in regulating the pace of cell generation. Brain Res Dev Brain Res. 1996;95:176-183.

36. Donatien P, Aigner B, Jeffery G. Variations in cell density in the ganglion cell layer of the retina as a function of ocular pigmentation. Eur J Neurosci. 2002;15:1597-1602.

37. Jeffery G, Kinsella B. Translaminar deficits in the retinae of albinos. J Comp Neurol. 1992;326:637-644.

38. Stone J, Rowe MH, Campion JE. Retinal abnormalities in the Siamese cat. J Comp Neurol. 1978;180:773-782.

39. Guillery RW, Hickey TL, Kaas JH, Felleman DJ, Debruyn EJ, Sparks DL. Abnormal central visual pathways in the brain of an albino green monkey (Cercopithecus aethiops). J Comp Neurol. 1984;226:165-183.

40. Guillery RW, Scott GL, Cattanach BM, Deol MS. Genetic mechanisms determining the central visual pathways of mice. Science. 1973;179:1014-1016.

41. Drager UC. Autoradiography of tritiated proline and fucose transported transneuronally from the eye to the visual cortex in pigmented and albino mice. Brain Res. 1974;82:284-292.

42. LaVail JH, Nixon RA, Sidman RL. Genetic control of retinal ganglion cell projections. J Comp Neurol. 1978;182:399-421.

43. Balkema GWJ, Pinto LH, Drager UC, Vanable JWJ. Characterization of abnormalities in the visual system of the mutant mouse pearl. J Neurosci. 1981;1:1320-1329.

44. Pak MW, Giolli RA, Pinto LH, Mangini NJ, Gregory KM, Vanable JWJ. Retinopretectal and accessory optic projections of normal mice and the $\mathrm{OKN}$-defective mutant mice beige, beige-J, and pearl. J Comp Neurol. 1987;258:435-446.

45. Rice DS, Williams RW, Goldowitz D. Genetic control of retinal projections in inbred strains of albino mice. J Comp Neurol. 1995;354:459-469.

46. Jeffery G, Schutz G, Montoliu L. Correction of abnormal retinal pathways found with albinism by introduction of a functional tyrosinase gene in transgenic mice. Dev Biol. 1994;166:460464.

47. Lavado A, Jeffery G, Tovar V, de la Villa P, Montoliu L. Ectopic expression of tyrosine hydroxylase in the pigmented epithelium rescues the retinal abnormalities and visual function common in albinos in the absence of melanin. J Neurochem. 2006;96:1201-1211.

48. Lund RD. Uncrossed visual pathways of hooded and albino rats. Science. 1965;149:1506-1507.

49. Giolli RA, Creel DJ. Inheritance and variability of the organization of the retinogeniculate projections in pigmented and albino rats. Brain Res. 1974;78:335-339.

50. Sanderson KJ. Retinogeniculate projections in the rabbits of the albino allelomorphic series1. J Comp Neurol. 1975;159: 15-27.

51. Guillery RW. An abnormal retinogeniculate projection in Siamese cats. Brain Res. 1969;14:739-741.

52. Guillery RW. An abnormal retinogeniculate projection in the albino ferret (Mustela furo). Brain Res. 1971;33:482-485.

53. Cucchiaro J, Guillery RW. The development of the retinogeniculate pathways in normal and albino ferrets. Proc $R$ Soc Lond B Biol Sci. 1984;223:141-164.

54. Guillery RW, Kaas JH. Genetic abnormality of the visual pathways in a "white" tiger. Science. 1973;180:1287-1289.

55. Yokoyama T, Silversides DW, Waymire KG, Kwon BS, Takeuchi T, Overbeek PA. Conserved cysteine to serine mutation in tyrosinase is responsible for the classical albino mutation in laboratory mice. Nucleic Acids Res. 1990;18:7293-7298.

56. Jimenez-Cervantes C, Solano F, Kobayashi T, et al. A new enzymatic function in the melanogenic pathway. The 5,6dihydroxyindole-2-carboxylic acid oxidase activity of tyrosi- nase-related protein-1 (TRP1). J Biol Chem. 1994;269:1799318000.

57. Kobayashi $\mathrm{T}$, Urabe $\mathrm{K}$, Winder $\mathrm{A}$, et al. Tyrosinase related protein 1 (TRP1) functions as a DHICA oxidase in melanin biosynthesis. EMBO J. 1994;13:5818-5825.

58. Mangini NJ, Vanable JWJ, Williams MA, Pinto LH. The optokinetic nystagmus and ocular pigmentation of hypopigmented mouse mutants. J Comp Neurol. 1985;241:191-209.

59. Shimizu N, Tabata H, Wada Y, et al. Distribution of optokinetic sensitivity across the retina of mice in relation to eye orientation. Neuroscience. 2010;168:200-208.

60. Optican LM, Zee DS. A hypothetical explanation of congenital nystagmus. Biol Cybern. 1984;50:119-134.

61. Collewijn H, Winterson BJ, Dubois MF. Optokinetic eye movements in albino rabbits: inversion in anterior visual field. Science. 1978;199:1351-1353.

62. Jacobs JB, Dell'Osso LF. Congenital nystagmus: hypotheses for its genesis and complex waveforms within a behavioral ocular motor system model. J Vis. 2004;4:604-625.

63. Huang YY, Rinner O, Hedinger P, Liu SC, Neuhauss SC. Oculomotor instabilities in zebrafish mutant belladonna: a behavioral model for congenital nystagmus caused by axonal misrouting. J Neurosci. 2006;26:9873-9880.

64. Rick JM, Horschke I, Neuhauss SC. Optokinetic behavior is reversed in achiasmatic mutant zebrafish larvae. Curr Biol. 2000; 10:595-598.

65. Huang MY, Chen CC, Huber-Reggi SP, Neuhauss SC, Straumann D. Comparison of infantile nystagmus syndrome in achiasmatic zebrafish and humans. Ann N Y Acad Sci. 2011;1233: 285-291.

66. St John R, Fisk JD, Timney B, Goodale MA. Eye movements of human albinos. Am J Optom Physiol Opt. 1984;61:377-385.

67. Collewijn H, Apkarian P, Spekreijse H. The oculomotor behaviour of human albinos. Brain. 1985;108:1-28

68. Mehdorn E, Schade K. Mechanism of "inversion" of optokinetic nystagmus and pursuit movement in congenital nystagmus [in German]. Fortschr Ophthalmol. 1988;85:285-288.

69. Kline LB, Arnold AC, Eggenberger E, et al. 2008-2009 Basic and Clinical Science Course: Section 5: Neuro-Ophthalmology. San Francisco, CA: American Academy of Opthalmology; 2008:27.

70. Balkema GW, Mangini NJ, Pinto LH, Vanable JWJ. Visually evoked eye movements in mouse mutants and inbred strains. A screening report. Invest Ophthalmol Vis Sci. 1984;25:795800 .

71. Sirkin DW, Hess BJ, Precht W. Optokinetic nystagmus in albino rats depends on stimulus pattern. Exp Brain Res. 1985;61: 218-221.

72. Kolpakov VG, Alekhina TA, Barykina NN, Chugui VF, Popova NK. Some physiological manifestations of the activity of the gene controlling the predisposition to pendulum-like movements in rats. Neurosci Behav Physiol. 2001;31:311-316.

73. Wong AA, Brown RE. Visual detection, pattern discrimination and visual acuity in 14 strains of mice. Genes Brain Behav. 2006;5:389-403.

74. Puk O, Dalke C, Hrabe de Angelis M, Graw J. Variation of the response to the optokinetic drum among various strains of mice. Front Biosci. 2008;13:6269-6275.

75. Redfern WS, Storey S, Tse K, et al. Evaluation of a convenient method of assessing rodent visual function in safety pharmacology studies: effects of sodium iodate on visual acuity and retinal morphology in albino and pigmented rats and mice. $J$ Pharmacol Toxicol Methods. 2011;63:102-114.

76. Barabas P, Huang W, Chen H, et al. Missing optomotor headturning reflex in the DBA/2J mouse. Invest Ophthalmol Vis Sci. 2011;52:6766-6773. 
77. Rangarajan KV, Lawhn-Heath C, Feng L, Kim TS, Cang J, Liu X. Detection of visual deficits in aging DBA/2J mice by two behavioral assays. Curr Eye Res. 2011;36:481-491.

78. Anderson MG, Smith RS, Hawes NL, et al. Mutations in genes encoding melanosomal proteins cause pigmentary glaucoma in DBA/2J mice. Nat Genet. 2002;30:81-85.

79. Lu H, Li L, Watson ER, et al. Complex interactions of Tyrp1 in the eye. Mol Vis. 2011;17:2455-2468.

80. Dell'Osso LF. Biologically relevant models of infantile nystagmus syndrome: the requirement for behavioral ocular motor system models. Semin Ophthalmol. 2006;21:71-77.

81. Harris C, Berry D. A developmental model of infantile nystagmus. Semin Ophthalmol. 2006;21:63-69.

82. Anderson JR. Causes and treatment of congenital eccentric nystagmus. Br J Ophthalmol. 1953;37:267-281.

83. McMullen CA, Andrade FH, Stahl JS. Functional and genomic changes in the mouse ocular motor system in response to light deprivation from birth. J Neurosci. 2004;24:161-169.

84. Tarpey P, Thomas S, Sarvananthan N, et al. Mutations in FRMD7, a newly identified member of the FERM family, cause X-linked idiopathic congenital nystagmus. Nat Genet. 2006;38: 1242-1244.

85. Watkins RJ, Thomas MG, Talbot CJ, Gottlob I, Shackleton S. The role of FRMD7 in idiopathic infantile nystagmus. $J$ Ophthalmol. 2012;2012:460956.
86. Betts-Henderson J, Bartesaghi S, Crosier M, et al. The nystagmus-associated FRMD7 gene regulates neuronal outgrowth and development. Hum Mol Genet. 2010;19:342-351.

87. Dell'Osso LF, Williams RW. Ocular motor abnormalities in achiasmatic mutant Belgian sheepdogs: unyoked eye movements in a mammal. Vision Res. 1995;35:109-116.

88. Dell'Osso LF, Williams RW, Jacobs JB, Erchul DM. The congenital and see-saw nystagmus in the prototypical achiasma of canines: comparison to the human achiasmatic prototype. Vision Res. 1998;38:1629-1641.

89. Acland GM, Aguirre GD, Ray J, et al. Gene therapy restores vision in a canine model of childhood blindness. Nat Genet. 2001;28:92-95.

90. Tusa RJ, Mustari MJ, Das VE, Boothe RG. Animal models for visual deprivation-induced strabismus and nystagmus. Ann $N$ Y Acad Sci. 2002;956:346-360.

91. Repka MX, Tusa RJ. Refractive error and axial length in a primate model of strabismus and congenital nystagmus. Invest Ophthalmol Vis Sci. 1995;36:2672-2677.

92. Waespe W, Cohen B, Raphan T. Dynamic modification of the vestibulo-ocular reflex by the nodulus and uvula. Science. 1985;228:199-202.

93. van der Geest JN, Frens MA. Recording eye movements with video-oculography and scleral search coils: a direct comparison of two methods. J Neurosci Methods. 2002;114:185-195. 